The International Journal of Engineering and Science (IJES)

|| Volume || 6 || Issue || 4 || Pages || PP 58-62 || 2017 ||

ISSN (e): $2319-1813$ ISSN (p): $2319-1805$

THE IJES

\title{
Desalination of Sea Water into Fresh Water Using Thermal and Tidal Power
}

\author{
Abhay Dixit \\ F. A. Author is with the maharishi Arvind College of engg. And research centre, Sirsi road Jaipur, Rajasthan, \\ India
}

\begin{abstract}
The salt water is being a problem for a long time with decrease in fresh water reservoirs it has become difficult to survive in the future. This paper concerned on using a clean energy for converting the saline water of sea into fresh water which can be used for drinking .The tidal energy of sea is being earlier used in order to generate electricity the spare water is being pumped back into the sea but if the spare water is being converted into steam using solar thermal power and the electricity produced by tidal power, then the evaporated water after cooling can be stored which can be used for drinking. The changes are been done in order to use the central receiver thermal power plant in order to produce power as well as clean source of drinking water without depleting the natural fossil fuels and without disturbing the environment.
\end{abstract}

Keywords: Thermal power plant, tidal energy.

\section{INTRODUCTION}

THE freshwater resources are nowadays increasingly short, seawater desalination is a new technique for freshwater resources replacement, has been highly admired by many countries and institutions. But in the area's such as Remote Island, due to the high input, high consumption, equipment complex reasons and degradation of natural resources, resulting in seawater desalination technology is not used in production and practiced; therefore the development of a clean energy-efficient desalination technique is close. In recent years, research on seawater desalination gradually increased the concern of researchers, and issues related to energy-efficient desalination has become a hot spot. Methods usually include seawater desalination by freezing method, electro dialysis, distillation, reverse osmosis.

This research paper concentrates on tackling issues like

- $\quad$ Scaling.

- Cost.

- $\quad$ Scarcity of fresh water.

- Flood

- Cyclones.

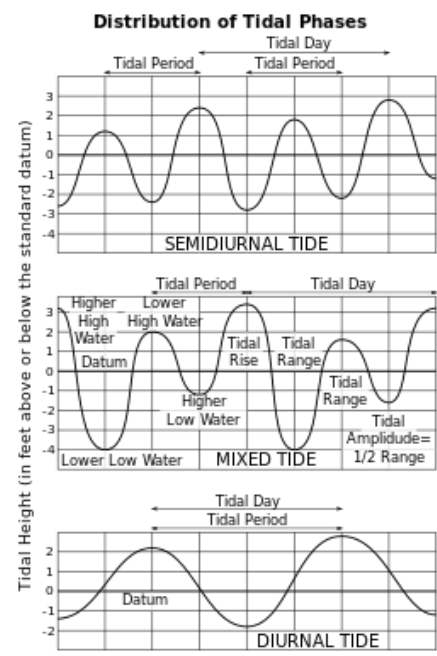

Fig. 1 Showing the Moon's declinational effect in production of semidiurnal, mixed, and diurnal tides 


\section{A. Solar Energy Power Plant}

For decades, to come the sun will grow in importance as one of the best alternatives for fossil fuel as a natural source of energy. The solar radiation on earth surface, though erratic due to cloud cover, discontinuous due to night and seasons; and diffuse but enough to provide energy for industrial process ,commercial building, private homes, electricity generation\& many other endless uses. Solar heating and cooling system have been commercialized. Large size solar thermal power plants (100MW) are in the developing stage.

There are two types of solar thermal electric power system:

- Central receiver thermal power plant

- Distributed collector solar thermal power plant.

1. Control Receiver Thermal Power Plant

The arrangement of a central receiver thermal power plant uses an optically transmits radiant solar energy from a reflector known as heliostat a centrally located receiver on a tall tower for converting water into steam the central receiver is an insulated enclosure with a slot opening of about $1 \times 4 \mathrm{~m}$ and with cooling tubes opposite the slot the radiation through slot can give rise to a very high temperature about 2000 degree Celsius .A part of steam is allowed to expand through a conventional turbine and the rest is utilized for thermal storage as a storage is essential requirement to take care variable solar radiation the use of storage facility helps the plant to produce electrical output at or near rated power continuously. The working cycle is Rankine Cycle and the system is known as "stand alone solar power plant "and most closely represents the manner in which conventional plant operate.

For example the solar energy power plant in California the principle of operation follows as The installation uses parabolic concave shaped with an open top, solar thermal science along with natural gas to generate electricity. About $90 \%$ of the electricity is produced by the sunlight. Natural gas is only used when the solar power is insufficient to meet the demand from Southern California Edison, the distributor of power in southern California. Mirrors used:

The parabolic mirrors are used. The sun rays falls onto the panels made of glass, which are $94 \%$ reflective, unlike a typical mirror, which is only $70 \%$ reflective. The mirrors automatically trace the sun throughout the day. The greatest source of mirror breakage is wind, with 3,000 mirrors are replaced each year. Operators can turn the mirrors to protect them during intense wind storms. An automated washing mechanism is used to periodically clean the parabolic reflective panels.

Heat transfer:-

The sunlight reflects off the mirrors and is directed to a central tube filled with synthetic oil, which heats to over $400{ }^{\circ} \mathrm{C}$ The reflected light focused at the central tube is 71 to 80 times more

As per my knowledge this idea of using the solar energy power plant and tidal power plant to produce fresh water and to get clean energy as a byproduct is not been considered and thought.

B. Tidal Energy

Tidal power, also called tidal energy, is a form of hydropower that converts the energy of tides into useful forms of power - mainly electricity.

Although till recent years not widely used, tidal power has potential for future electricity generation. Tides are been more predictable than wind energy and solar power. Among other sources of renewable energy, tidal power has relatively high cost and limited availability of sites with sufficiently high tidal ranges or flow velocities, thus resisting its total availability. However, many recent technological developments and improvements, both in design and turbine technology, increases the availability of tidal power than previously thought, and that economic and environmental costs may be brought down to competitive levels. Tidal energy is unconventional never ending energy source.

Tidal power conventionally involves constructing a dam across the opening to a tidal basin. The dam includes a sluice that is opened to allow the tide to flow into the basin; the sluice is then closed, and as the sea level drops, conventional hydropower is produced which can be used to generate electricity from the elevated water in the basin.

The energy potential of tidal basins is voluminous - the largest facility, the La Rance station in France, generates 240 megawatts of power. Currently, France is the only country that successfully uses this power source. French engineers have noted that if the use of tidal power on a global level was brought to high enough levels, the Earth would slow its rotation by 24 hours in every 2,000 years.

Tidal energy systems can have environmental impacts on tidal basins because of reduced tidal flow and silt buildup.

3 Ways of Using the Tidal Power of the Ocean

There are three basic ways to tap the ocean for its energy. We can use the ocean's waves, we can use the ocean's high and low tides, or we can use temperature differences in the water.

Wave Energy:- 
Kinetic energy is present in the moving waves of the ocean. That energy can be used to move the shaft of a turbine.

When the wave goes down, air flows through the turbine and back into the chamber through doors that are normally closed.

This is only one type of wave-energy system. Others actually use the up and down motion of the wave to power a piston that moves up and down inside a cylinder. That piston can also turn a generator.

Most wave-energy systems are very small. But, they can be used to power a small light house.

Ocean Thermal Energy:-

The ocean energy idea uses temperature difference, in the ocean Power plants can be built that use the difference in temperature to make energy. A difference of at least 38 degrees Fahrenheit is needed between the warmer surface water and the colder deep ocean water. Using this type of energy source is called Ocean Thermal Energy Conversion or OTEC. It is being used in both Japan and in Hawaii in some projects.

Tidal Energy:-

Another form of ocean energy is called tidal energy. When tides come onto the shore, they can be trapped in reservoirs behind dams. Then when the tide drops, the water behind the dam can be let out just like in a regular hydroelectric power plant.

In order for this to work well, we need large increase in tides. A difference of 16" is required between the low tide and high tide. There are only a few places in the world where this tide change can occur. Some power plants are already operating using this idea. One plant in France makes enough energy from tides to power 240,000 homes.

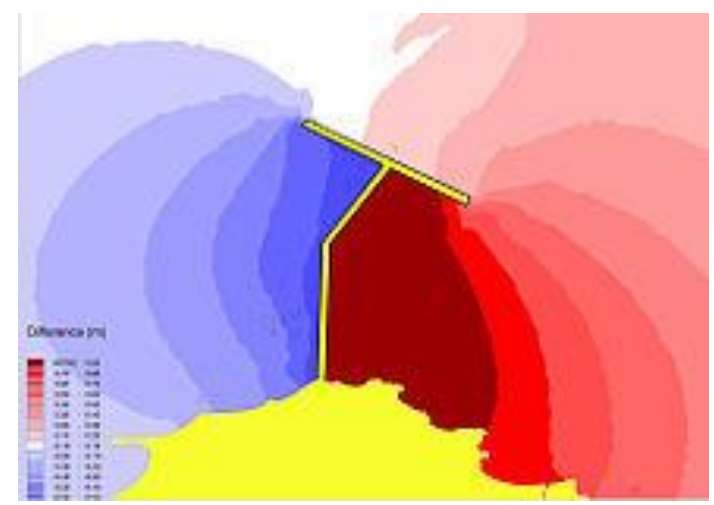

Fig 2 - shows down view of a dam, Blue and dark red colors shows low and high tides, respectively.

Tides in the ocean are caused by the joint action of sun and moon there are normally 2 high tides a day ,each about 12 hours \& 25 minutes apart the change in level between high and low tides produces available energy provide sufficient water can be impounded at high tide and released at low tides through a water turbine.

The single basin schemes suffer from the drawback that they can only generate power for part of a time due to discontinuous effect of the tides .the two basin schemes produces continuous power at the cost of extra capital cost.

Tidal power is reliable, clean source of renewable energy the plant at la Rance in France has been operational for about 20 years producing $240 \mathrm{MW}$ of power.

\section{C.Ohmic Heating}

Joule heating, also known as ohmic heating and resistive heating, is the process in which the flow of an electric current through a conductor produces heat. The amount of heat produced is proportional to the square of the current such that

This relationship is known as Joule's first law. The SI unit of this energy was named the joule and the symbol is J. The commonly known unit of power, the watt, is equivalent to one joule per second. Joule heating is independent of the direction of current.

Joule heating is caused by interactions between the moving particles that form the current and the atomic ions that forms the body of the conductor. Charged particles in an electric circuit are accelerated by an electric field but give up some of their kinetic energy each time they collide with an ion. The vibration energy of the ions provide evidence itself for heat and a rise in the temperature of the conductor. Hence energy is transferred from the electrical power supply to the conductor and any materials with which it is in thermal contact.

Joule heating is referred to as ohmic heating or resistive heating because of its relationship to Ohm's Law. It forms the basis for the large number of practical applications involving electric heating. However, in applications where heating is an unwanted by-product of current use, the diversion of energy is often linked to as resistive loss. The use of high voltages in electric power transmission systems is specifically designed to reduce such 
losses in cabling by operating with equal measure or extent lower currents. The ring circuits, or ring mains, used in UK homes are another example, where power is delivered to outlets at lower currents, thus reducing it. Joule heating does not occur in superconducting materials, as these materials have zero resistance in the superconducting state.

Resistors create electrical noise, called Johnson-Nyquist noise.

As a heating technology, Joule heating has a coefficient of performance of 1.0, which means that that every joule of electrical energy supplied produces one joule of heat. In contrast, a heat pump can have a coefficient of more than 1.0 since it moves additional thermal energy from the environment to the heated item

\section{THEORY}

The high tides and low tides are basically forms by the gravitation field of moon with that the high tides are formed, and when the moon is set, i.e. when the sun rises the, tides tends to move back that are used in order to rotate the shafts of generator which convert's the mechanical energy into electric energy since the mechanical work is been done by rotating the shafts of turbine which is connected to the generator. Therefore the electricity produced by the tides is been stored.

The solar radiation is erratic due to cloud cover, discontinuous due to night and seasons, therefore using the electricity produced by tidal power and using it to produce heating will solve the above problem. Now using the principle given by "JAMES PRESCOTT JULE"

$\mathrm{H} \propto \mathrm{I}^{2}$ (CURRENT),

$\mathrm{H} \alpha \mathrm{R}$ (RESISTANCE),

$\mathrm{H} \alpha \mathrm{T}$,

Therefore, $\mathrm{H}=\mathrm{I}^{2} \mathrm{RT}$.

This is also known as "HEATING EFFECT OF CURRENT".

The electricity produced in order to heats up the sea water.

The aluminum pipes is been used in the piping of thermal power plant in order to increase the temperature of the water, the sea water is being pumped into the assembly comprising of the aluminum pipes which are used in the thermal power plant, thermal power plant converts the sea water into vapors /steam a small amount of steam is transferred to rotates the turbine which also produces electricity and other major part of steam is cooled down to obtain water. In winter season and cloudy days or in nights electricity produced by tidal power is to be used which will increase the temperature inside the pipes, therefore the evaporation process starts leaving the salt in the pipes and the evaporated water i.e. the water vapors are collected separately.

Therefore, water vapors produced are cooled down in order to collect the water that is pure and drinkable in nature.

\section{PROCEDURE}

The tides are attracted by moon's gravitational field, therefore when the tides are high enough then close the chamber, which consists of shafts, so that the shaft start rotating the current so produced are stored so the generator starts producing electricity.

- When the tides are low, they tend to move back therefore again the shaft rotates and the generator starts producing current.

Now, with the chamber closed the sea water is pumped into the assembly of solar energy power plant with aluminum pipes fitting with the help of an electric pump in order to cope with the potential difference.

The interior temperature of the central receiver thermal power plant rises up to 510 degree, which converts the sea water into steam /vapor Formby

- $\quad$ The steam so produced rotates the shafts of the turbine which is attached to the generator in order to produce to electricity.

The steam so produced in the above step is cooled down and taken out.

- The main constitute of sea water is salt (sodium chloride) therefore when the phase of water changes its leaves behind salt.

- $\quad$ Therefore the salt is removed from the sea water.

\section{PROBLEMS}

- $\quad$ Scaling problem.

- No solar radiation in winter season.

- Cost is high. 


\section{REMEDIES}

The electricity produced by tidal power in hot seasons and by steam can be sold in order to account for cost of establishment. Second the in winter season heating effect of current can be used to convert sea water into fresh water. For scaling each section of aluminum pipe have to clean separately or any sticking agent have to be applied in the interior parts of the pipes.

\section{ADVANTAGES}

- $\quad$ Clean source of energy.

- Water is desalinated.

- $\quad$ Salt is produced.

- $\quad$ The imbalance caused by the melting of polar caps can be controlled which will help in the controlling the formation of cyclones and hurricanes.

- $\quad$ Flood management.

\section{CONCLUSION}

The desalination of sea water using solar thermal power plant and tidal power can be used in order to produce clean energy, drinkable water\& salt and will help in controlling environmental problems such as cyclones, flood.

\section{REFERENCES}

[1]Veera Gnaneswar Gude, Nirmalakhandan Shuguang Deng and Anand Maganti, Applied Energy, 91, 466-474, 2012 Low Temperature Desalination using Solar Collectors Augmented in Thermal Energy Storage.

[2] American Journal of environmental sciences 01/2008-An Applied Research Program on Water Desalination with Renewable Energies by Sergio M. Alcocer and Gerardo Hiriart.

[3] Basic electrical energy by v.k.mehta\&rohit Mehta.

[4]British -hydro la Rance BHA -Oct 2009.

[5]Chang, Jen (2008), Hydrodynamic Modeling and Feasibility Study of Harnessing Tidal Power at the Bay of Fundy (PhD thesis), Los Angeles: University of Southern California retrieved 2011-09-27.

[6]K. Bourouni, M.T. Chaibi, L. Tadrist, Desalination 137 (2001) 167-176 Water desalination by humidification and dehumidification of air: State of the art.

[7]V. Belessiotis, E. Delyannis, Desalination 139 (2001) 133-138 Water shortage and renewable energies (RE) desalination possible technological applications

[8] Steam \& gas turbines and power plant engineering by Dr.R .YADAV.

[9]09/2011; SET2011, 10th International Conference on Sustainable Energy Technologies Seawater Desalination using Solar Thermal Technologies: state of the art by Shiva Gorjian, Teymour Tavakkoli Hashjin, Barat Ghobadian

[10] Renewable and Sustainable Energy Reviews, Volume 22, June 2013, Page 735 RETRACTED: Fresh water production from/by atmospheric air for arid regions, using solar energy by A.M.K. El-Ghonemy.

[11] EIA (2009). International Energy Outlook .Washington D, C.US Department of energy.

[12] Tides and current chapter 4 - Variations in the Range of the Tides: Tidal Inequalities.

[13] Cohen, Gilbert (2006). "Nevada First Solar Electric Generating System" (PDF).IEEE May Technical Meeting. Las Vegas, Nevada: Solargenix Energy. p. 10.

[14] Frier, Scott (1999). "An overview of the Kramer Junction SEGS recent performance" (PDF). Parabolic Trough Workshop. Ontario, California: KJC Operating Company.

[15] Kearney, D. (August 1989). "Solar Electric Generating Stations (SEGS)". IEEE Power Engineering Review (IEEE) 9 (8): $4-8$. doi:10.1109/MPER.1989.4310850.

[16] Price, Hank (2002). "Parabolic trough technology overview" (PDF). Trough Technology - Algeria. NREL. p. 9.

[17] Minchinton, W. E. (October 1979). "Early Tide Mills: Some Problems". Technology and Culture (Society for the History of Technology) 20 (4): 777-786. doi:10.2307/3103639.JSTOR 3103639

[18] Dorf, Richard (1981). The Energy Factbook. New York: McGraw-Hill.

[19] DiCerto, JJ (1976). The Electric Wishing Well: The Solution to the Energy Crisis. New York: Macmillan.

[20] Turcotte, D. L.; Schubert, G. (2002). "4". Geodynamics (2 ed.). Cambridge, England, UK: Cambridge University Press. pp. $136-137$. ISBN 978-0-521-66624-4.

[21] George E. Williams (2000). "Geological constraints on the Precambrian history of Earth's rotation and the Moon's orbit". Reviews of Geophysics 38 (1): 37-60.Bibcode:2000RvGeo..38...37W. doi:10.1029/1999RG900016.

[22] Electric power systems: a conceptual introduction by Alexandra von Meier, p67, Google books link

[23] Ramaswamy, Raghupathy. "Ohmic Heating of Foods". Ohio State University. Retrieved 2013-04-22.

[24] R.J.Oosterbaan, J.Boonstra and K.V.G.K.Rao (1996). The energy balance of groundwater flow. In: V.P.Singh and B.Kumar (eds.), Subsurface-Water Hydrology, Vol.2 of the Proceedings of the International Conference on Hydrology and Water Resources, New Delhi, India. Kluwer Academic Publishers, Dordrecht, The Netherlands. pp. 153-160. ISBN 978-0-7923-3651-8 